Systematic Review

\title{
Both low and high knee flexion angles during tibial graft fixation yield comparable outcomes following ACL reconstruction with quadriceps tendon autograft: A systematic review
}

\author{
Hassaan Abdel Khalik, MD ${ }^{\mathrm{a}}$, Darius L. Lameire, MD ${ }^{\mathrm{a}}$, Jeffrey Kay, MD ${ }^{\mathrm{b}}$, Sachin R. Tapasvi, MD ${ }^{\mathrm{c}}$, \\ Kristian Samuelsson, $\mathrm{PhD}^{\mathrm{d}}$, Darren de Sa, FRCSC ${ }^{\mathrm{b}, "}$ \\ ${ }^{a}$ Michael G. DeGroote School of Medicine, McMaster University, Hamilton, Ontario, Canada \\ ${ }^{\mathrm{b}}$ Division of Orthopaedic Surgery, McMaster University, Hamilton, Ontario, Canada \\ ${ }^{\mathrm{c}}$ Department of Arthroplasty and Arthroscopy, The Orthopaedic Specialty Clinic, Pune, Maharashtra, India \\ d Department of Orthopaedics, Institute of Clinical Sciences, The Sahlgrenska Academy, University of Gothenburg, Gothenburg, Sweden
}

\section{A R T I C L E I N F O}

\section{Keywords:}

Anterior cruciate ligament

Arthroscopy

Quadriceps tendon

Autografts

Knee

\begin{abstract}
A B S T R A C T
Importance: A paucity of clinical evidence surrounds the effect of the knee flexion angle during tibial fixation of the graft during anterior cruciate ligament (ACL) reconstruction. While biomechanical studies have recently sought to revive this area of study in both single- and double-bundle graft populations, they have done so using variants of the hamstring graft. This does not shed light on the optimal fixation of other autograft options, namely, the quadriceps tendon (QT) autograft.

Objectives: To determine the effect of the knee flexion angle during tibial graft fixation on functional and clinical outcomes following ACL reconstruction using single-bundle QT autograft, inclusive of both soft-tissue and boneplug graft types.

Evidence review: An electronic search of MEDLINE, EMBASE, Web of Science, and the Cochrane Library was carried out from database inception to June 2020. Following study screening, patient demographics and fixation technique as well as both subjective and objective clinical outcomes were abstracted. Studies were divided based on the knee flexion angle during tibial fixation of the graft. The low knee flexion angle (L-KFA) group included patients with a tibial fixation angle of $<30^{\circ}$ of flexion, and the high knee flexion (H-KFA) group included those with a tibial fixation of exactly $30^{\circ}$ of flexion. The data were qualitatively synthesized due to significant heterogeneity across the included studies.

Findings: Sixteen studies (1,169 patients) were included for analysis. There were 675 patients in the L-KFA group (mean age range, 18.7-34.5 years) and 494 patients in the H-KFA group (mean age range, of 23.2-32.1 years). Both groups yielded statistically significant improvements from preoperative to postoperative scores across several functional and clinical outcomes. Return to pre-injury activity levels ranged from $64 \%$ to $81 \%$ in L-KFA studies and from $73.3 \%$ to $86.7 \%$ in H-KFA studies. All-cause graft failure rates ranged from $1.4 \%$ to $4.3 \%$ in LFKA studies and from $0 \%-10.7 \%$ in H-KFA studies.

Conclusion: Both low- and high-knee flexion angles during tibial graft fixation produce improved postoperative clinical and functional outcomes with comparable outcomes across groups. There is inconclusive evidence to recommend the ideal knee flexion angle for graft fixation in primary ACLR.

Level of evidence: Level IV.
\end{abstract}

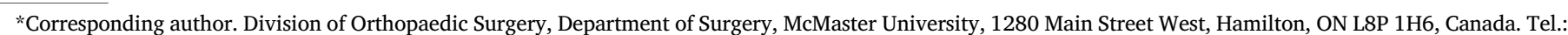
+1365366 7638 .

E-mail address: darren.desa@medportal.ca (D. de Sa). 


\section{What is already known?}

- Biomechanics studies have demonstrated that the knee flexion angle during tibial fixation of the graft during ACL reconstruction impacts various postoperative knee outcomes including, but not limited to, post-operative knee range of motion, in situ forces of the graft, and rotational knee stability

\section{What are the new findings?}

- Tibial fixation of a single-bundle quadriceps tendon autograft at both low and high knee flexion angles produces improved and comparable patient-reported and objective outcomes following ACL reconstruction

- Graft failure rates were comparable across both low and high knee flexion angles during tibial fixation of the graft during ACL reconstruction

\section{Introduction}

Anterior cruciate ligament (ACL) tears continue to be one of the most common orthopaedic injuries in the United States [1]. Orthopaedic surgeons can choose from several graft types [2] and surgical techniques [3, 4] when performing ACL reconstruction (ACLR). Though the patellar tendon and hamstring grafts have been historically more commonly used, the quadriceps tendon (QT) autograft has been recently gaining popularity due to its flexibility, ease of harvest, decreased donor-site morbidity, and favorable outcomes [5,6]. Several surgical techniques have been described for tibial fixation of the graft. Variables associated with these techniques include the use of interference screws, cortical fixation or cross pin fixation, the type of tunnel placement, and the knee flexion angle (KFA) during tibial graft fixation [7-10].

The effects of the knee flexion angle (KFA) during tibial graft fixation on knee biomechanics and clinical outcomes following ACLR have been evaluated for $>30$ years. The literature suggests two primary approaches to KFA during graft fixation: (1) fixation at full or near extension [8,9] and (2) fixation at $30^{\circ}$ of flexion [10]. Proponents of low knee flexion angles may cite decreased rates of postoperative flexion contractures relative to high KFAs [8,11,12], a decreased likelihood of over constraining over-constraining the graft [13], and decreased in situ graft forces [14,15]. Proponents of graft fixation and tensioning at higher KFAs, specifically $30^{\circ}$ degrees, may cite closer to normal in situ graft forces [15], better restoration of rotational knee stability relative to low KFAs [16], and reduced anterior tibial translation (ATT) relative to low KFAs [15].

There remains a paucity of clinical studies or systematic reviews examining the effects of KFA on postoperative clinical and functional outcomes, especially pertaining to the QT autograft [16-20]. Therefore, this review aims to determine the effect of the knee flexion angle during tibial graft fixation on functional and clinical outcomes following ACLR using a single-bundle quadriceps tendon autograft, inclusive of both soft-tissue and bone-plug graft types. We assumed the null hypothesis, specifically, that there will be no difference in clinical or functional outcomes across either a KFA of $<30^{\circ}$ and a KFA of $30^{\circ}$, with similar rates of loss of extension across both groups.

\section{Materials and methods}

Comprehensive search strategy

This review followed the guidelines and algorithm of the Preferred Reporting Items for Systematic Reviews and Meta-analyses (PRISMA)
[21]. A systematic search of MEDLINE, EMBASE, Web of Science, and the Cochrane Controlled Register of Trials (CENTRAL) was performed through June 30, 2020 by two reviewers (HAK and DLL) for literature related to anterior cruciate ligament reconstruction using quadriceps tendon. All studies published since 2000 were included. The search terms included 'anterior cruciate ligament', 'reconstruction', and 'quadriceps tendon'. The complete search strategies used for each database can be found in Appendix A. The inclusion criteria for this review were [1] primary anterior cruciate reconstruction, [2] single-bundle quadriceps tendon reconstruction with or without bone plug, [3] ipsilateral autograft, [4] outcomes data provided, [5] reported flexion angle during tibial graft fixation, [6] skeletally mature patients, [7] all levels of evidence, [8] human studies, and [9] studies published in English. Exclusion criteria consisted of [1] revision ACL reconstruction, [2] cadaveric studies, [3] biomechanical studies, [4] multi-ligamentous knee reconstruction, [5] no follow-up/outcomes data reported, [6] published before the year 2000, [7] double-bundle quadriceps tendon ACL reconstruction, and [8] review articles.

\section{Study screening}

The titles and abstracts of the identified studies were independently screened by two authors (HAK and DLL) using the inclusion and exclusion criteria. When necessary (i.e., insufficient data within the abstract), full-text review was performed. Disagreements were advanced to the fulltext review stage to prevent premature exclusion. Any full-text disagreement was resolved by consulting a senior third author (DdS) and arriving at a consensus across all of the reviewers. After each screening state, a Kappa ( $\kappa$ ) score was calculated to determine the level of agreement between reviewers along with a $95 \%$ confidence interval (CI). A $\kappa$ score of $\geq 0.81$ signifies almost perfect agreement, a $\kappa$ score between 0.61 and 0.8 represents substantial agreement, and a $\kappa$ score of $<0.61$ represents between moderate to poor agreement [22].

\section{Assessment of study quality}

The methodological quality of randomized control trials and prospective randomized trials were assessed using The Cochrane Collaboration's tool for assessing risk of bias in randomised trials by two authors (HAK and DLL) independently. The items on the questionnaire were determined as "low risk of bias," "high risk of bias," or "unclear risk of bias". Any disagreements were resolved by the third author (DdS) [23]. The quality of the non-randomized studies was assessed using the Methodological Index for Non-randomized Studies (MINORS) [24]. The studies were assessed independently by two authors (HAK and DLL), and the scores were averaged (Table 1 ).

\section{Data abstraction from included studies}

Each reviewer abstracted data from half of the studies, with the second reviewer checking for accuracy, and vice versa. The data were abstracted and recorded into predetermined tables using Google Sheets. The following data were abstracted from the studies if available: study characteristics (journal, author, publication year, study design, level of evidence [LOE]), number of patients, follow-up length, participant characteristics (e.g., age, sex, etc.), details of the surgery performed (flexion angle during graft fixation, graft type), and both subjective and objective clinical outcomes. Subjective clinical outcomes included (1) International Knee Documentation Committee (IKDC) subjective score, (2) IKDC activity levels, (3) Lysholm score, and (4) Tegner Activity Score. Objective clinical outcomes included (1) anterior drawer test, (2) Lachman test, (3) pivot-shift test, (4) anteroposterior (AP) side-to-side difference, and (5) AP translation. Additional outcomes included range of motion deficits, return to sport/pre-injury activity levels, and graft failure or rupture rates. Further details regarding the reported subjective and objective clinical outcomes can be found in Appendix B. The LOE of each 
Table 1

Characteristics of included studies.

\begin{tabular}{|c|c|c|c|c|c|c|c|c|c|c|}
\hline Author (Year) & Country & Study design & LOE & Patients & Knees & $\begin{array}{l}\text { Average } \\
\text { follow-up, } \\
\text { Mo } \\
\text { (minimum } \\
\text { follow-up, } \\
\text { Mo) }\end{array}$ & $\begin{array}{l}\text { Mean age, } \\
\text { Yr }\end{array}$ & Male, \% & $\begin{array}{l}\text { Tibial } \\
\text { fixation } \\
\text { knee flexion } \\
\text { angle, }^{\circ}\end{array}$ & $\begin{array}{l}\text { Mean } \\
\text { MINORS } \\
\text { score }\end{array}$ \\
\hline Akoto (2012) [29] & Germany & Case series & IV & 30 & 30 & NR (12) & 31.0 & $57 \%$ & 30 & 10.5 \\
\hline Barie (2020) [30] & Germany & $\mathrm{RCT}$ & II & 30 & 30 & 12.2 (NR) & 30.5 & $57 \%$ & 0 & N/A \\
\hline Cavaignac (2017) [37] & Switzerland & Cohort & III & 50 & 50 & 40.8 (NR) & 32.1 & $60 \%$ & 30 & 19.5 \\
\hline Chen (2006) [38] & Taiwan & Case series & IV & 38 & 38 & $62.0(\mathrm{NR})$ & 26.0 & $68 \%$ & 0 & 11.0 \\
\hline Galan (2020) [39] & Argentina & Cohort & III & 291 & 291 & NR (72) & 23.2 & $92 \%$ & 30 & 11.5 \\
\hline Geib (2009) [40] & United States & Case series & IV & 191 & 198 & $55.6(24)$ & 31.7 & $53 \%$ & $20-30$ & 17.0 \\
\hline Gorschewsky (2007) [35] & Switzerland & Cohort & III & 124 & 124 & 34.0 (NR) & NR & NR & 0 & 19.0 \\
\hline Han (2008) [41] & South Korea & Cohort & III & 72 & 72 & 39.7 (NR) & 27.8 & $94 \%$ & 0 & 20.5 \\
\hline \multicolumn{11}{|l|}{$\operatorname{Kim}(2018)$ [42] } \\
\hline+ Remnant & South Korea & Cohort & III & 42 & 42 & 17.9 (NR) & 30.3 & $83 \%$ & 30 & 18.5 \\
\hline - Remnant & South Korea & Cohort & III & 33 & 33 & $18.2(\mathrm{NR})$ & 26.0 & $85 \%$ & 30 & 18.5 \\
\hline $\operatorname{Kim}(2009)$ [36] & South Korea & Cohort & III & 28 & 28 & NR (24) & 26.1 & $79 \%$ & $10-15$ & 20.0 \\
\hline Kwak (2018) [43] & South Korea & Cohort & IV & 45 & 45 & $29.8(24.9)$ & 34.5 & $84 \%$ & 0 & 18.0 \\
\hline Lee (2016) [44] & South Korea & Cohort & III & 48 & 48 & $35.6(\mathrm{NR})$ & 31.1 & $92 \%$ & 30 & 18.5 \\
\hline Lee (2004) [31] & South Korea & Case series & IV & 67 & 67 & 41.0 (NR) & 28.0 & $87 \%$ & 0 & 12.0 \\
\hline Lund (2014) [32] & Denmark & RCT & II & 26 & 26 & NR (24) & 30.0 & $81 \%$ & 20 & N/A \\
\hline Martin-Alguacil (2018) [33] & Spain & RCT & II & 26 & 26 & NR (24) & 18.7 & $88 \%$ & 20 & N/A \\
\hline Perez (2019) [34] & United States & Cohort & III & 28 & 28 & $31.6(24)$ & 23.1 & $61 \%$ & 10 & 19.5 \\
\hline
\end{tabular}

LOE, level of evidence; NR, not reported; RCT, randomized control trial.

article was classified based on the authors statement, and in cases in which they did not state the LOE, we classified the LOE based on the American Academy of Orthopaedic Surgeons (AAOS) Evidence-Based Practice Committee guidelines [25].
Studies that reported ACL reconstruction failures were categorized into three categories. Graft failure is defined as an atraumatic graft failure based on subjective or clinical outcomes (i.e., increased laxity), graft rupture is defined as a traumatic tear of the ACL due to injury, and
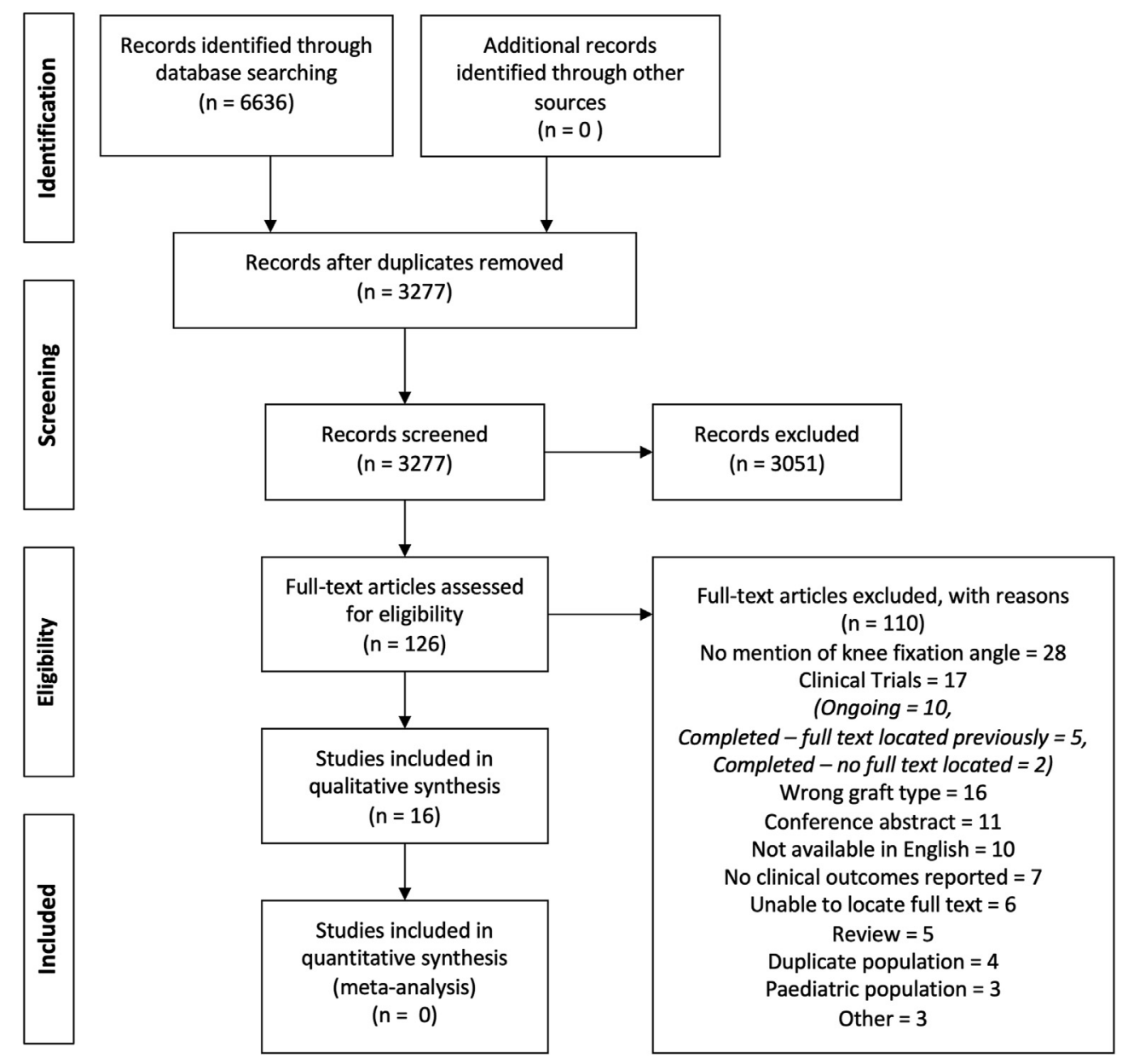

Fig. 1. Outline of systematic search strategy. 
unclear graft failure/rupture was used to categorize all graft complications without clear causation [26].

\section{Statistical analysis}

The included studies were divided into two groups based on the knee flexion angle when fixating the graft to the tibia. The low flexion angle group (L-KFA) included patients with a knee flexion angle of $<30^{\circ}$ during fixation, and the high flexion angle group (H-KFA) included those with a knee flexion angle of exactly $30^{\circ}$. A threshold angle of $30^{\circ}$ was based on previous biomechanical studies evaluating the effect of KFA on knee stability and in situ forces following ACLR using various singlebundle grafts [11,13-16]. At minimum, these studies evaluated the aforementioned outcomes following KFAs of $0^{\circ}$ and $30^{\circ}$ of flexion. As such, this systematic review similarly proceeded with two comparative groups separated by a $30^{\circ}$ of flexion threshold. Further, none of the included studies performed tibial fixation of the graft at a knee flexion angle of $>30^{\circ}$.

Due to the significant heterogeneity between the included studies with variations in patient population, length of follow-up, surgical technique, surgeons, and graft type, we did not pool the data in a metaanalysis. Instead, all outcomes consistently reported have been presented in forest plots. Additionally, a subgroup analysis of objective knee outcomes was performed comparing L-KFA and H-KFA studies across transtibial and anatomic ACLR techniques to account for reported variations in the aforementioned techniques' anteroposterior and rotational stability outcomes $[27,28]$.

\section{Results}

There were an initial 6,636 studies that resulted from the search of MEDLINE, EMBASE, Web of Science, and CENTRAL, with 3,277 remaining after exclusion of duplicates. After screening using the inclusion and exclusion criteria, there were 16 studies that were used for this review (Fig. 1) [29-44]. The title and abstract screening had substantial inter-reviewer agreement as the $\kappa$ score was 0.73 (95\% CI, 0.66-0.80), and there was almost perfect agreement after the full text screening, with a $k$ score of 0.84 (95\% CI, 0.72-0.95). Any studies that cited surgical techniques had the subsequent techniques reviewed for KFA. The risk of bias assessment for the randomized studies is presented in Fig. 2. The average MINORS score for comparative studies is $18.9( \pm 1.1)$, or moderate quality, and $11.3( \pm 0.6)$, or moderate quality, for non-comparative studies (Table 1).

The included studies comprised 1,169 patients (1,176 knees) with an average age ranging from 18.7 to 34.5 years at the time of ACLR with a quadriceps tendon graft. There were 675 patients in the L-KFA tibial fixation group with a fixation angle of $<30^{\circ}$, with no study reporting fixation in hyperextension. The mean age range was $18.7-34.5$ years, the percentage of male patients ranged from $53 \%$ to $94 \%$, and the average follow-up ranged from 12.2 to 62 months postoperatively. There were 494 patients in the H-KFA tibial fixation group with a reported fixation angle of $30^{\circ}$. The mean age range was $23.2-32.1$ years, the percentage of male patients ranged from $57 \%$ to $92 \%$, and the average follow-up ranged from 17.9 to 40.8 months postoperatively (Table 1 ).

\section{Characterization of surgical technique}

The majority of patients in the L-KFA group underwent a form of transtibial drilling of the femoral tunnel (647 patients) [30-33,35,36,38, $40,41,43]$, with one study using the anteromedial portal technique (28 patients) [34]. In the H-KFA group, there were two studies using a form of the transtibial technique (123 patients) [42,44], two studies using a form of the anteromedial technique (321 patients) [29,39], and one study using the outside-in method (50 patients) [37]. Further details regarding the use of a bone block as well as the anchoring devices used for femoral and/or tibial fixation of the graft can be found in Table 2.
Subjective clinical outcomes

Included subjective clinical outcomes were IKDC scores, IKDC activity levels, Lysholm scores, and Tegner activity scores. The details of preoperative and postoperative subjective scores reported across the included studies are available in Table 3. Postoperative mean IKDC scores ranged from 67.3 to 94.8 [30,32,34,37,43] and from 70.1 to $86.1[29,42,44]$ in L-KFA and H-KFA groups, respectively (Fig. 3). Postoperative Lysholm scores ranged from 87.0 to $95.6[30,33-36,38,41,43]$ and from 89.0 to $92.1[37,39,42,44]$ in L-KFA and H-KFA groups, respectively (Fig. 4). One study in the L-KFA group reported a mean postoperative Tegner score of 6.0 [34], while three studies in the H-KFA group reported scores ranging from 4.1 to $5.9[37,42,44]$.

\section{Objective clinical outcomes}

Included objective clinical outcomes were the anterior drawer test, Lachman test, pivot-shift test, and anteroposterior translation. The details of preoperative and postoperative objective scores reported across the included studies are available in Table 4. Two L-KFA studies reporting postoperative anterior drawer test outcomes found $96 \%-100 \%$ of knees to be either grade I or grade II [31,43]. Two H-KFA studies reporting postoperative anterior drawer test outcomes found $98 \%-100 \%$ of knees to be either grade I or II $[42,44]$. Four L-KFA studies reported postoperative Lachman grading, and the percentage of grade-I or II laxity ranged from $96 \%$ to $98 \%[31,36,38,43]$. Two H-KFA studies reported postoperative Lachman grading, and the percentage of grade-I or II laxity ranged from $98 \%$ to $100 \%[42,44]$. Three L-KFA studies reported postoperative pivot-shift grading, and the percentage of grade-I or II knees ranged from $96 \%$ to that $100 \%[31,36,43]$. Three H-KFA reported post-operative pivot-shift grading, and all reported that $100 \%$ of knees were either grade I or II $[37,42,44]$. Anteroposterior side-to-side differences ranged from $0.94 \mathrm{~mm}$ to $2.64 \mathrm{~mm}$ [30,32,36,40,43] and from $1.0 \mathrm{~mm}$ to $2.21 \mathrm{~mm}[29,37,39,42,44]$ in the L-KFA and H-KFA groups, respectively (Fig. 5). Subgroup analysis of transtibial technique studies across the L-KFA and H-KFA groups found comparable results across the

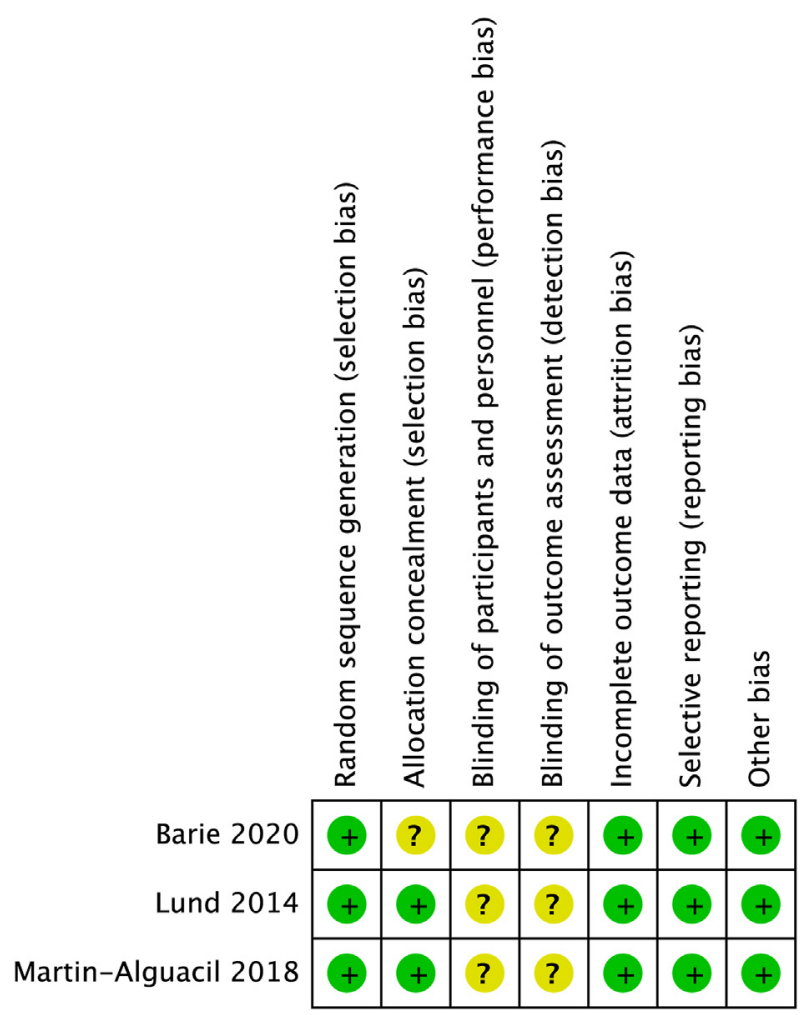

Fig. 2. Risk of bias assessment. 
Table 2

Characteristics of surgical and fixation techniques used in included studies.

\begin{tabular}{|c|c|c|c|c|c|}
\hline $\begin{array}{l}\text { Tibial } \\
\text { fixation } \\
\text { knee flexion } \\
\text { angle }\end{array}$ & Study & ACLR technique & Bone block & Anchoring device, femoral side & Anchoring device, tibial side \\
\hline \multirow[t]{11}{*}{$<30^{\circ}$} & Barie (2020) & Transtibial & Yes & Press-fit & $\begin{array}{l}\text { Hybrid (bone wedge }+ \text { sutures tied } \\
\text { over bone bridge) }\end{array}$ \\
\hline & Chen (2006) & Transtibial & Yes & Interference screw (NR) & Bicortical screw and washer \\
\hline & $\begin{array}{l}\text { Gorschewsky } \\
\text { (2007) }\end{array}$ & Transtibial & Yes & Interference screw (absorbable) & Interference screw (absorbable) \\
\hline & Geib (2009) & Transtibial & Combined & Interference screw (absorbable) & Interference screw (absorbable) \\
\hline & Han (2008) & Transtibial & Yes & Interference screw (metal) & Interference screw (absorbable) \\
\hline & Kim (2009) & Transtibial & Yes & Interference screw (absorbable) & Interference screw (absorbable) \\
\hline & Kwak (2018) & $\begin{array}{l}\text { Modified transtibial } \\
\text { technique }\end{array}$ & Yes & Interference screw (metal) & Interference screw (metal) \\
\hline & Lee (2004) & Transtibial & Yes & Interference screw (metal) & Interference screw (absorbable) \\
\hline & Lund (2014) & Transtibial & Yes & Interference screw (metal) & Interference screw (metal) \\
\hline & $\begin{array}{l}\text { Martin-Alguacil } \\
\text { (2018) }\end{array}$ & Transtibial & No & Interference screw (absorbable) & Interference screw (absorbable) \\
\hline & Perez (2019) & $\begin{array}{l}\text { Anteromedial portal } \\
\text { technique }\end{array}$ & No & Loop suspensory cortical fixation & $\begin{array}{l}\text { Interference screw (non-absorbable } \\
\text { polymer) }\end{array}$ \\
\hline \multirow[t]{5}{*}{$30^{\circ}$} & Akoto (2012) & Anteromedial portal & Yes & Press-fit & $\begin{array}{l}\text { Split bone wedge }+ \text { sutures tied over } \\
\text { bone bridge }+ \text { distal bone plug press- } \\
\text { fit anterior tibial tunnel }\end{array}$ \\
\hline & $\begin{array}{l}\text { Cavaignac } \\
(2017)\end{array}$ & Outside-in method & Yes & Interference screw (absorbable) & Interference screw (absorbable) \\
\hline & Galan (2020) & $\begin{array}{l}\text { All-inside technique } \\
\text { (anteromedial portal) }\end{array}$ & Yes & Interference screw (NR) & Retroscrew \\
\hline & $\begin{array}{l}\text { Kim (2018) } \\
(+/- \text { Remnant })\end{array}$ & $\begin{array}{l}\text { Modified transtibial } \\
\text { technique }\end{array}$ & Yes & Interference screw (metal) & Interference screw (absorbable) \\
\hline & Lee (2016) & Transtibial & Yes & Interference screw (metal) & Interference screw (absorbable) \\
\hline
\end{tabular}

NR, not reported.

Lachman test, pivot-shift test, and side-to-side anteroposterior translation (Appendix C). No subgroup analysis was performed across anatomic technique studies due to a lack of objective outcomes reported in the L-KFA group.

\section{Range of motion deficits}

Five studies in the L-KFA group reported on postoperative limitations in knee extension. One study reported limitations of knee extension in $3.3 \%$ of patients due to the development of cyclops lesions, which were re-operated on, ultimately leading to full extension [30]. One study reported that $4.2 \%$ of patients had a deficit of $<5^{\circ}$ and that one patient (1.4\%) had a $10^{\circ}$ extension deficit [41]. One study reported that $3.6 \%$ of patients had a deficit of $>5^{\circ}$ [36]. Another study reported that $3 \%$ of patients had an extension deficit of $>3^{\circ}$ [31]. One study in the H-KFA group reported that 1 patient (3.3\%) had an extension deficit of $>3^{\circ}$ [29].

Six studies in the L-KFA group reported on postoperative flexion deficits. In studies defining flexion as a loss of $\geq 5^{\circ}$, flexion deficit rates ranged from $3 \%$ to $4.2 \%[36,38,41]$. Among those studies, one knee was specified to experience a flexion deficit of $6^{\circ}$ to $15^{\circ}$ [38], another knee experienced a flexion deficit of $10^{\circ}$ [41], and the third knee experienced a flexion deficit of $40^{\circ}$ [41]. One additional reported a mean postoperative flexion deficit of $0.3^{\circ}$ [40]. Lastly, one study reported a $99 \%$ flexion loss rate defined as $<5^{\circ}$ [31]. One study in the H-KFA group reported a mild flexion loss rate of $3.3 \%$, although the degrees of flexion were not specified [29].

\section{Return to sport/pre-injury activity levels}

Two studies in the L-KFA group reported return to sport or pre-injury activity rates. One study reported return to pre-injury levels based on the Tegner score, with $64 \%$ of patients achieving their pre-injury Tegner score [30]. Another study reported an $81 \%$ return to sport rate [35]. Two studies in the H-KFA group reported return to pre-injury activity rates ranging from $73.3 \%$ to $86.7 \%$ based on the Tegner score $[29,39]$.
Table 3

Preoperative and postoperative patient reported outcomes.

\begin{tabular}{|c|c|c|c|}
\hline & Preoperative & Postoperative & $P$ value \\
\hline \multicolumn{4}{|l|}{$<30^{\circ}$} \\
\hline \multicolumn{4}{|c|}{ IKDC subjective score (mean \pm SD) } \\
\hline Kwak (2018) & $42.7 \pm 22.6$ & $67.3 \pm 16.8$ & $<0.001$ \\
\hline \multicolumn{4}{|c|}{ IKDC activity levels (strenuous: moderate: light: sedentary) } \\
\hline Chen (2006) & $5: 4: 6: 19$ & $17: 9: 5: 3$ & NR \\
\hline Kim (2009) & $3: 5: 15: 5$ & $11: 13: 4: 0$ & $<0.05$ \\
\hline Lee (2004) & $11: 54: 2: 0$ & $9: 50: 8: 0$ & NR \\
\hline \multicolumn{4}{|l|}{ Lysholm (mean $\pm \mathrm{SD})$} \\
\hline Barie (2020) & $59.7 \pm 18.6$ & $95.6 \pm 7.8$ & NR \\
\hline Chen (2006) & $61.4 \pm 8.9$ & $93.0 \pm 7.9$ & $<0.05$ \\
\hline Han (2008) & $70.7 \pm \mathrm{NR}$ & $91.5 \pm 9.7$ & NR \\
\hline Kim (2009) & $75.8 \pm 8.2$ & $91.8 \pm 9.7$ & $<0.05$ \\
\hline Kwak (2018) & $62.4 \pm 8.4$ & $87.0 \pm 5.3$ & $<0.001$ \\
\hline Lee (2004) & 71 & 90 & $<0.05$ \\
\hline Martin-Alguacil (2018) & $76.3 \pm \mathrm{NR}$ & $93.8 \pm \mathrm{NR}$ & NR \\
\hline \multicolumn{4}{|l|}{ Tegner (median, IQR) } \\
\hline Barie (2020) & $4,0-8$ & $6,4-9$ & 0.645 \\
\hline Kwak (2018) & $2.8,1.8-4.0$ & $7.2,6.3-8.2$ & $<0.001$ \\
\hline \multicolumn{4}{|l|}{$30^{\circ}$} \\
\hline \multicolumn{4}{|c|}{ IKDC subjective score (mean \pm SD) } \\
\hline Kim (2018) + Remnant Group & $44.3 \pm 17.7$ & $70.1 \pm 9.1$ & $<0.001$ \\
\hline Kim (2018) - Remnant Group & $51.9 \pm 16.9$ & $72.3 \pm 10.1$ & $<0.001$ \\
\hline Lee (2016) & $60.3 \pm 17.8$ & $80.2 \pm 10.0$ & $<0.001$ \\
\hline \multicolumn{4}{|l|}{ Lysholm (mean $\pm S D)$} \\
\hline Galan (2020) & $64.0 \pm 6.1$ & $91.0 \pm 6.1$ & NR \\
\hline Kim (2018) + Remnant Group & $68.4 \pm 20.5$ & $90.1 \pm 7.0$ & $<0.001$ \\
\hline Kim (2018) - Remnant Group & $73.6 \pm 13.7$ & $89.3 \pm 10.7$ & $<0.001$ \\
\hline Lee (2016) & $70.2 \pm 9.6$ & $92.1 \pm 8.7$ & $<0.001$ \\
\hline \multicolumn{4}{|l|}{ Tegner $($ mean $\pm S D)$} \\
\hline Kim (2018) + Remnant Group & $3.9 \pm 2.0$ & $4.2 \pm 1.1$ & n.s. \\
\hline Kim (2018) - Remnant Group & $3.6 \pm 1.9$ & $4.1 \pm 1.4$ & n.s. \\
\hline Lee (2016) & $4.6 \pm 1.8$ & $4.7 \pm 1.2$ & 0.819 \\
\hline
\end{tabular}

NR, not reported; n.s., not significant. 


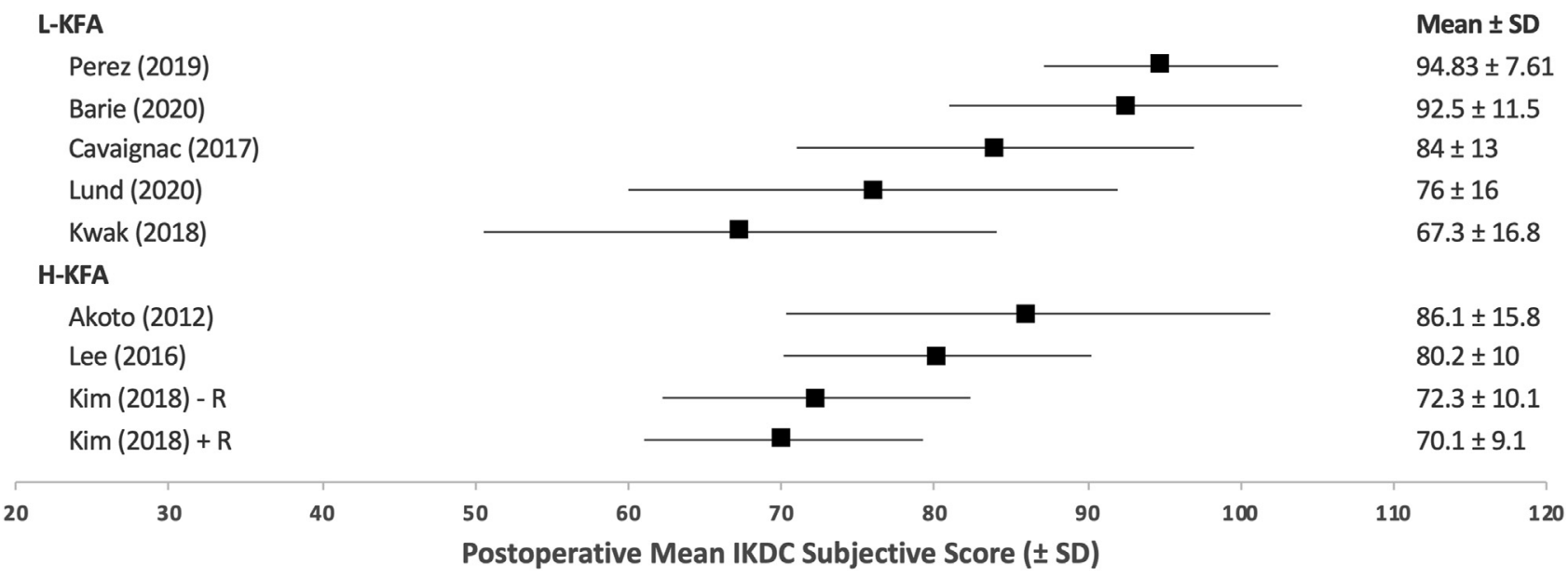

Fig. 3. Postoperative mean IKDC subjective scores across both low- and high-knee flexion groups.

\section{Graft failure or rupture}

Graft failure rates defined as atraumatic persistent laxity and ranged from $1.4 \%$ to $4.5 \%$ in the L-KFA group [31,36,40,41], with no H-KFA studies reporting this outcome. Graft rupture rates ranged from $1.4 \%$ to $3.8 \%[31,33,35,41]$ and from $0 \%$ to $2 \%[29,37,42]$ in the L-KFA and H-KFA groups, respectively. Rates of unclear mechanisms of graft failure/rupture ranged from $3.3 \%$ to $4.3 \%$ in the L-KFA group [30,34], with one H-KFA study reporting a rate of $10.7 \%$ [39].

\section{Discussion}

The key finding of this systematic review is that both low and high knee flexion angles during tibial graft fixation produce comparable clinical and functional outcomes following single-bundle QT autograft ACLR, with statistically significant improvements from preoperative to postoperative evaluations. Furthermore, both L-KFA and H-KFA groups experienced similarly low rates of extension and flexion deficits, with several cases of extension deficit in the L-KFA group being attributable to cyclops deformities independent of the knee flexion angle. Both L-KFA and H-KFA knees experienced comparable rates of return to pre-injury activity levels as well as low rates of all-cause graft failure rates.

To date, several biomechanical studies have sought to examine the impact of the knee flexion angle during tibial graft fixation on single- bundle graft function. A notable study that assessed knee kinematics (specifically, anterior tibial translation) and in situ graft forces across four knee positions during tibial graft fixation found that $30^{\circ}$ of flexion with a 134-N posterior force best replicated knee kinematics and in situ graft forces observed in the native knee [15]. Additional positions examined were (1) full extension, (2) $30^{\circ}$ of flexion with no posterior load applied, and (3) $30^{\circ}$ of flexion with $67 \mathrm{~N}$ of posterior load applied. Only four studies included in this review reported the use of posterior loading and lacked the specific force used, thus preventing any meaningful analysis $[31,34,37,42]$. Furthermore, a recent study that sought to examine the effects of the knee flexion angle during graft fixation on rotational knee stability found that $30^{\circ}$ of flexion during anatomic ACLR best restored rotational stability relative to (1) anatomic reconstruction in full extension, (2) non-anatomic reconstruction in $30^{\circ}$ flexion, and (3) non-anatomic reconstruction in full extension [16]. With regard to the relationship of graft fixation angle and the position of the tibia relative to the femur, it has been demonstrated that graft fixation at $20^{\circ}$ best replicated normal knee positioning compared to graft fixation at $0^{\circ}$ and $90^{\circ}$ [19]. Despite the strong evidence trending towards high KFAs during tibial graft fixation, a study that sought to examine the effects of knee flexion, initial graft tension, and femoral graft attachment site on graft forces and anteroposterior stability concluded that graft fixation at full extension $44 \mathrm{~N}$ of tension produce similar outcomes relative to the intact knee [13]. Furthermore, grafts fixed at $30^{\circ}$ flexion were over-constrained

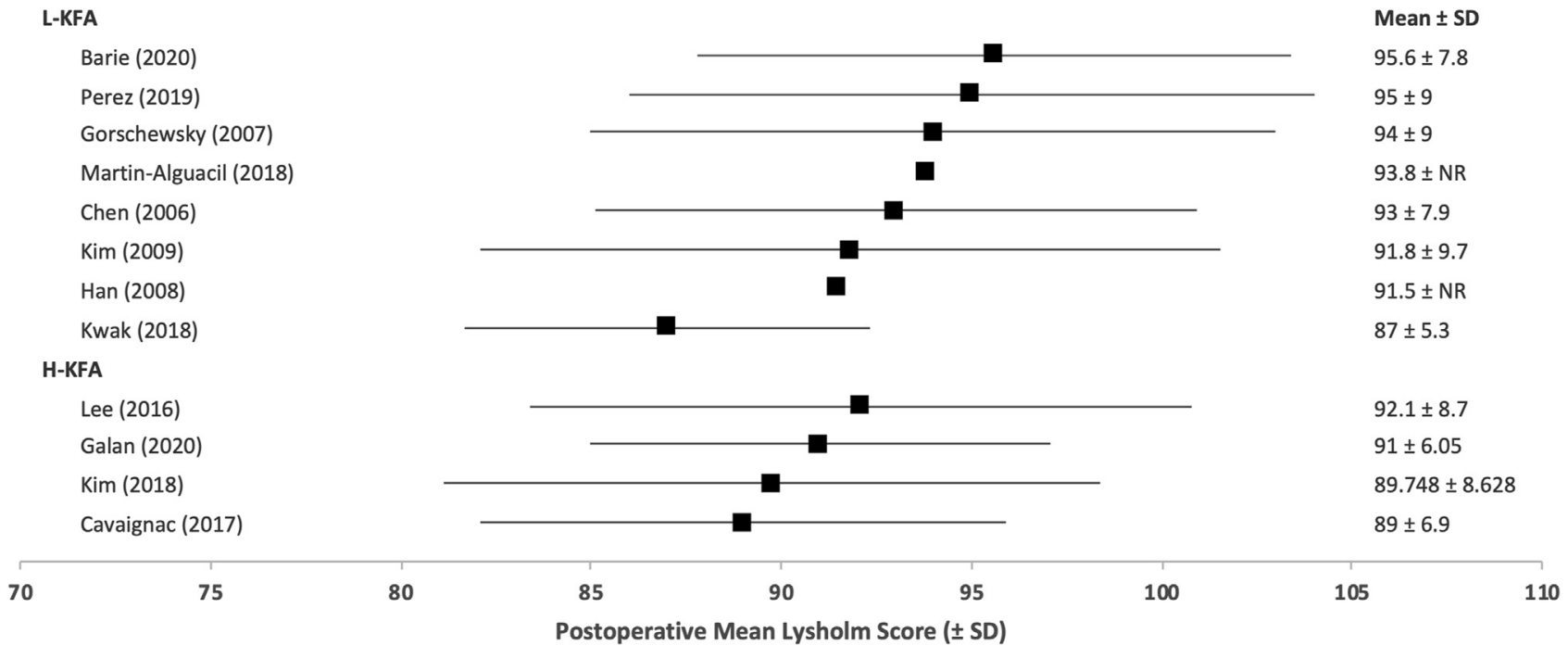

Fig. 4. Postoperative mean Lysholm scores across both low- and high-knee flexion groups. 
Table 4

Preoperative and postoperative objective clinical outcomes.

\begin{tabular}{|c|c|c|c|}
\hline & Preoperative & Postoperative & p-value \\
\hline \multicolumn{4}{|l|}{$<30^{\circ}$} \\
\hline \multicolumn{4}{|c|}{ Anterior drawer test (grade I:II:III:IV) } \\
\hline Kwak (2018) & $4: 15: 21: 5$ & 32:13:0:0 & $<0.001$ \\
\hline Lee (2004) & $0: 11: 50: 6$ & $50: 14: 3: 0$ & NR \\
\hline \multicolumn{4}{|l|}{ Lachman test (grade I:II:III:IV) } \\
\hline Chen (2006) & $0: 0: 24: 10$ & $30: 3: 1: 0$ & NR \\
\hline Kim (2009) & $0: 2: 21: 5$ & $23: 4: 1: 0$ & NR \\
\hline Kwak (2018) & 3:14:19:9 & 29:15:1:0 & $<0.001$ \\
\hline Lee (2004) & $0: 10: 52: 4$ & 47:17:3:0 & NR \\
\hline \multicolumn{4}{|l|}{ Pivot-shift test (grade I:II:III:IV) } \\
\hline Kim (2009) & $0: 1: 24: 3$ & $24: 3: 1: 0$ & NR \\
\hline Kwak (2018) & $4: 22: 14: 5$ & 29:16:0:0 & $<0.001$ \\
\hline Lee (2004) & $0: 11: 42: 14$ & 41:23:3:0 & NR \\
\hline \multicolumn{4}{|c|}{ AP side-to-side difference, $\mathrm{mm}($ mean $\pm \mathrm{SD})$} \\
\hline Barie (2020) & $5.0 \pm 1.4$ & $1.0 \pm 1.1$ & NR \\
\hline Kwak (2018) & $4.5 \pm 1.8$ & $1.8 \pm 1.6$ & $<0.001$ \\
\hline \multicolumn{4}{|l|}{ AP translation, $\mathrm{mm}$ (mean $\pm \mathrm{SD})$} \\
\hline Chen (2006) & $11.9 \pm 1.1$ & $1.7 \pm 1.8$ & $<0.01$ \\
\hline Lee (2004) & $7.2 \pm \mathrm{NR}$ & $2.1 \pm \mathrm{NR}$ & $<0.05$ \\
\hline Martin-Alguacil (2018) & $5.4 \pm \mathrm{NR}$ & $3.3 \pm \mathrm{NR}$ & NR \\
\hline \multicolumn{4}{|l|}{ 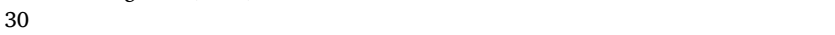 } \\
\hline \multicolumn{4}{|c|}{ Anterior drawer test (grade I:II:III:IV) } \\
\hline Kim (2018) + Remnant Group & $3: 21: 16: 2$ & 31:11:0:0 & $<0.001$ \\
\hline Kim (2018) - Remnant Group & $2: 22: 8: 1$ & $27: 6: 0: 0$ & $<0.001$ \\
\hline Lee (2016) & $5: 25: 15: 3$ & 34:13:1:0 & $<0.001$ \\
\hline \multicolumn{4}{|l|}{ Lachman test (grade I:II:III:IV) } \\
\hline Kim (2018) + Remnant Group & $0: 25: 1: 0$ & $36: 6: 0: 0$ & $<0.001$ \\
\hline Kim (2018) - Remnant Group & $2: 14: 14: 3$ & 24:9:0:0 & $<0.001$ \\
\hline Lee (2016) & $6: 23: 17: 2$ & $32: 15: 1: 0$ & $<0.001$ \\
\hline \multicolumn{4}{|l|}{ Pivot-shift test (grade I:II:III:IV) } \\
\hline Kim (2018) + Remnant Group & $1: 16: 24: 1$ & $32: 10: 0: 0$ & $<0.001$ \\
\hline Kim (2018) - Remnant Group & $0: 7: 19: 7$ & $23: 10: 0: 0$ & $<0.001$ \\
\hline Lee (2016) & $12: 15: 19: 2$ & $32: 16: 0: 0$ & $<0.001$ \\
\hline \multicolumn{4}{|c|}{ AP side-to-side difference, $\mathrm{mm}$ (mean $\pm \mathrm{SD}$ ) } \\
\hline Kim (2018) + Remnant Group & $3.5 \pm 2.1$ & $2.3 \pm 1.7$ & $<0.001$ \\
\hline Kim (2018) - Remnant Group & $3.2 \pm 1.6$ & $2.1 \pm 1.6$ & $<0.001$ \\
\hline Lee (2016) & $3.9 \pm 1.5$ & $2.1 \pm 1.9$ & $<0.001$ \\
\hline
\end{tabular}

NR, not reported; n.s., not significant

regardless of the tension applied, which results in the tibia being more posterior relative to the intact knee. While there is a robust foundation of biomechanical literature examining the effects of the knee flexion angle during graft fixation on graft function, there remains to be a clear consensus regarding the optimal KFA during tibial graft fixation. Additionally, further high-quality in vivo studies are necessary to draw similar conclusions in the clinical setting given the limitations of cadaveric robotic studies, including the inability to replicate functional loading of the knee as well as not adequately accounting for in vivo variables that could affect long-term graft function (e.g., graft healing, patient demographics, activity levels).

When assessing the impact of graft tensioning during tibial graft fixation on ACLR outcomes, one cannot overlook the possible impact of the femoral positioning of the graft resulting from the ACLR technique utilized by the surgeon. The transtibial technique is a commonly used ACLR technique that has been recently called into question due to not replicating the ACL's native oblique orientation, with subsequently hindered rotatory stability of the knee $[45,46]$ and high rates of revision surgery [47]. The present review found that the knee flexion angle produced comparable objective clinical outcomes across both L-KFA and H-KFA groups. Recently, the anatomic reconstruction of the ACL has gained traction in the orthopaedic surgery community due to more favorable clinical outcomes, ranging from improved rotatory stability and decreased tibial translation in the short term [28] to reduced rates of post-traumatic osteoarthritis in the long term [48]. The present review lacked an adequate sample size to run a subgroup analysis evaluating the effect of the knee flexion angle during tibial graft fixation in anatomic ACLR techniques. Looking ahead, investigators evaluating the effect of the knee flexion angle during tibial graft fixation are encouraged to make the clear distinction between transtibial and anatomic ACLR techniques in order to minimize any possible confounding factors.

A challenging aspect of establishing the ideal knee flexion angle during tibial graft fixation is the trade-off between knee stability and range of motion. While the present review lacked sufficient data to draw any conclusions regarding this relationship, a clinical study found that grafts fixed at $30^{\circ}$ of flexion presented with superior stability measures, but with significantly inferior range of motion outcomes, relative to grafts fixed at full extension [11]. Similar findings were reported in an in vivo study that found increasingly normal anterior stability and anterior tibial position were correlated with increases in extension deficits relative to the contralateral knee [49].

This review is not without its limitations. First, this systematic review only evaluated the effect of the knee flexion angle during tibial graft fixation when using the QT autograft. Therefore, the findings of this study may not be generalizable to other ACLR graft choices. Second, the included studies comprised several surgical techniques, including various ACLR techniques (anatomic ACLR, transtibial ACLR, etc.) as well as graft fixation methods (with or without bone plugs, bioabsorbable vs. metal interference screws, etc.), all of which could have impacted the selected outcomes. While studies have demonstrated conflicting findings regarding the impact of ACLR technique on outcomes [50,51], there do not appear to be any notable differences in clinical and functional outcomes pertaining to the use of metal versus interference screws [52-54], the use of aperture versus suspensory fixation [55], or the use of press-fit fixation [56]. Additionally, this review's subgroup analysis across transtibial L-KFA and H-KFA studies demonstrated comparable objective clinical outcomes across both groups. Furthermore, no difference in outcomes has been demonstrated across ACLR with full- or partial-thickness QT autografts [57]. Third, the method of measuring the knee flexion angle during tibial graft fixation was not always explicitly reported; therefore, variation within studies may exist. Last, included studies were primarily non-comparative Level-III or IV evidence, preventing any pooling or meta-analysis of outcomes. As such, conclusions should only be drawn while appropriately considering the quality of evidence in the studies cited.

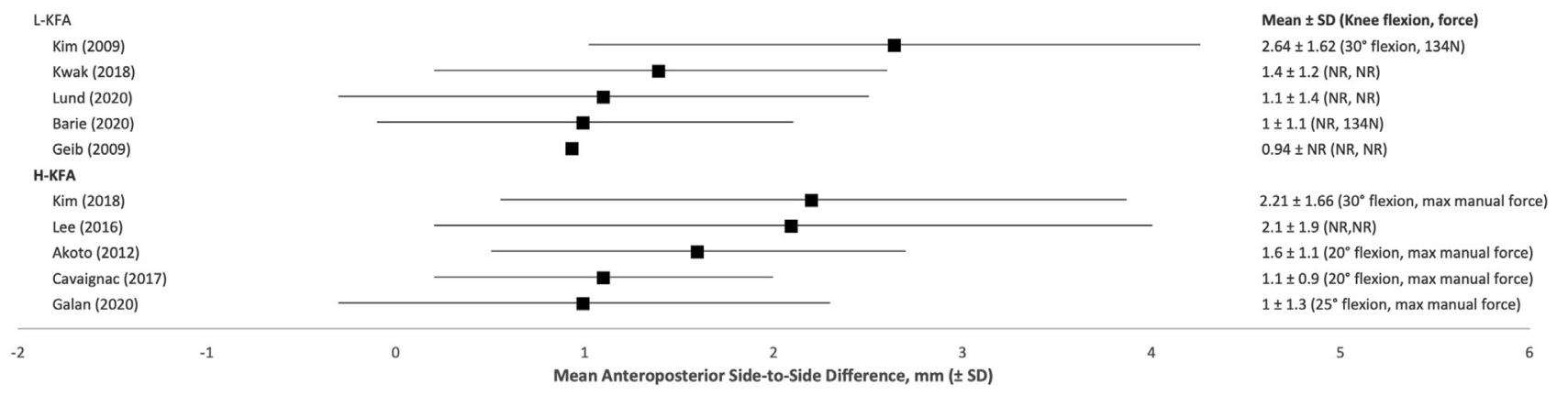

Fig. 5. Postoperative mean anteroposterior side-to-side difference across both low- and high-knee flexion groups. 


\section{Conclusion}

Both low and high knee flexion angles during tibial graft fixation produce improved postoperative clinical and functional outcomes, with comparable outcomes across groups. There is inconclusive evidence to recommend the ideal knee flexion angle for graft fixation in primary ACLR.

\section{Author's contribution}

All authors contributed equally in the design, execution, and finalization of this manuscript.

\section{Declaration of competing interest}

None.

\section{Appendix A. Search strategy}

\begin{tabular}{|c|c|c|}
\hline MEDLINE & Web of science & CENTRAL \\
\hline $\begin{array}{l}\text { 1. Anterior cruciate } \\
\text { ligament.mp. or } \\
\text { Anterior Cruciate } \\
\text { Ligament/ } \\
\text { 2. Reconstruction.mp. } \\
\text { or Anterior } \\
\text { Cruciate Ligament } \\
\text { Reconstruction/ } \\
\text { 3. Recon*.mp. } \\
\text { 4. Arthroscopic*.mp. } \\
\text { 5. Quad*.mp. } \\
\text { 6. Repair*.mp. } \\
\text { 7. } 2 \text { or } 3 \text { or } 4 \text { or } 6 \\
\text { 8. acl.mp. } \\
\text { 9. } 1 \text { or } 8 \\
\text { 10. } 5 \text { and } 7 \text { and } 9 \\
\text { 11. } 10 \text { not (animals/not } \\
\text { (humans/and animals/)) }\end{array}$ & $\begin{array}{l}\text { TS }=(\text { ACL OR } \\
\text { anterior cruciate } \\
\text { ligament) AND } \\
\text { TS = (recon* } \\
\text { OR arthroscop*) } \\
\text { AND TS }=\left(\text { quad }^{*}\right)\end{array}$ & $\begin{array}{l}\text { ("ACL" or "anterior } \\
\text { cruciate ligament") } \\
\text { and ("quadriceps") }\end{array}$ \\
\hline
\end{tabular}

\section{Appendix B. Definitions of subjective and objective clinical outcomes}

\section{Subjectve clinical outcomes}

The IKDC subjective score is a validated patient-outcomes questionnaire developed to detect the improvement or deterioration of knee function and symptoms after knee impairment [58,59]. The Lysholm score evaluates outcomes of knee ligament surgery and knee instability on a 0 to 100 scale, with the maximum score of 100 representing no symptoms or disability $[60,61]$. The Tegner Activity Score focuses on work and sporting activities on a 0 to 10 scale, representing the ability to participate in sports on an elite level [60].

\section{Objective clinical outcomes}

Studies that reported anterior drawer and Lachman test results graded laxity based on a scale of I, II, III, of IV, with I representing mild laxity of up to $5 \mathrm{~mm}$, II representing moderate laxity with 5-10 $\mathrm{mm}$ of translation, III representing severe laxity with $10-15 \mathrm{~mm}$ of translation, and IV representing gross laxity of $>15 \mathrm{~mm}$ [62]. The pivot-shift test was graded on a I-IV scale, with I representing no slip or jerk; II representing a slip but no jerk; III representing an obvious jump, thud, or jerk; and IV representing gross subluxation that requires the examiner to stop their assessment [62]. Studies that reported anteroposterior translation used either the KT-1000 (MEDmetric ${ }^{\circledR}$ Corp., San Diego, CA, USA) or the KT-2000 (MEDmetric ${ }^{\circledR}$ Corp., San Diego, CA, USA), using either 134 $\mathrm{lb}$ or maximal manual force.

\section{Appendix C. Objective outcomes sub-group analysis}

\begin{tabular}{|c|c|c|c|c|c|c|}
\hline & \multicolumn{3}{|c|}{ L-KFA } & \multicolumn{3}{|c|}{ H-KFA } \\
\hline & N.S. & Min & Max & N.S. & Min & Max \\
\hline & \multicolumn{6}{|c|}{ Trans-tibial technique } \\
\hline Lachman test, grade I + II & 4 & $96 \%$ & $98 \%$ & 2 & $98 \%$ & $100 \%$ \\
\hline Pivot shift, grade I + II & 3 & $96 \%$ & $100 \%$ & 2 & $100 \%$ & $100 \%$ \\
\hline Side-to-side AP translation, $\mathrm{mm}$ & 5 & 0.94 & 2.64 & 2 & 2.1 & 2.21 \\
\hline
\end{tabular}

\section{References}

[1] Kaeding CC, Léger-St-Jean B, Magnussen RA. Epidemiology and diagnosis of anterior cruciate ligament injuries. Clin Sports Med 2017;36(1):1-8. https:// doi.org/10.1016/j.csm.2016.08.001.

[2] Foster TE, Wolfe BL, Ryan S, Silvestri L, Krall Kaye E. Does the graft source really matter in the outcome of patients undergoing anterior cruciate ligament reconstruction?: an evaluation of autograft versus allograft reconstruction results: a systematic review. Am J Sports Med 2010;38(1):189-99. https://doi.org/10.1177/ 0363546509356530.

[3] Chalmers PN, Mall NA, Cole BJ, Verma NN, Bush-Joseph CA, Bach BR. Anteromedial versus transtibial tunnel drilling in anterior cruciate ligament reconstructions: a systematic review. Arthroscopy 2013;29(7):1235-42. https:// doi.org/10.1016/j.arthro.2013.02.015.

[4] Mascarenhas R, Cvetanovich GL, Sayegh ET, et al. Does double-bundle anterior cruciate ligament reconstruction improve postoperative knee stability compared with single-bundle techniques? A systematic review of overlapping meta-analyses. Arthroscopy 2015;31(6):1185-96. https://doi.org/10.1016/j.arthro.2014.11.014.

[5] Heffron WM, Hunnicutt JL, Xerogeanes JW, Woolf SK, Slone HS. Systematic review of publications regarding quadriceps tendon autograft use in anterior cruciate ligament reconstruction. Arthrosc Sport Med Rehabil 2019;1(1):e93-9. https:// doi.org/10.1016/j.asmr.2019.09.001.

[6] Mouarbes D, Menetrey J, Marot V, Courtot L, Berard E, Cavaignac E. Anterior cruciate ligament reconstruction: a systematic review and meta-analysis of outcomes for quadriceps tendon autograft versus bone-patellar tendon-bone and hamstring-tendon autografts. Am J Sports Med 2019;47(14):3531-40. https:// doi.org/10.1177/0363546518825340.

[7] Prodromos CC, Fu FH, Howell SM, Johnson DH, Lawhorn K. Controversies in softtissue anterior cruciate ligament reconstruction: grafts, bundles, tunnels, fixation, and harvest. J Am Acad Orthop Surg 2008;16(7):376-84. https://doi.org/10.5435/ 00124635-200807000-00003.

[8] Nabors ED, Richmond JC, Vannah WM, Mcconville OR. Anterior cruciate ligament graft tensioning in full extension. Am J Sports Med 1995;23(4):488-92. https:// doi.org/10.1177/036354659502300420.

[9] Grøntvedt T, Pena F, Engebretsen L. Accuracy of femoral tunnel placement and resulting graft force using one- or two-incision drill guides. A cadaver study on ten paired knees. Arthroscopy 1996;12(2):187-92. https://doi.org/10.1016/s07498063(96)90009-2.

[10] Markolf KL, Burchfield DM, Shapiro MM, Cha CW, Finerman GA, Slauterbeck JL. Biomechanical consequences of replacement of the anterior cruciate ligament with a patellar ligament allograft. Part II: forces in the graft compared with forces in the intact ligament. J Bone Jt Surg Am 1996;78(11):1728-34. https://doi.org/ 10.2106/00004623-199611000-00014.

[11] Asahina S, Muneta T, Ishibashi T, Yamamoto H. Effects of knee flexion angle at graft fixation on the outcome of anterior cruciate ligament reconstruction. Arthroscopy 1996;12(1):70-5. https://doi.org/10.1016/s0749-8063(96)90222-4.

[12] Austin JC, Phornphutkul C, Wojtys EM. Loss of knee extension after anterior cruciate ligament reconstruction: effects of knee position and graft tensioning. J Bone Jt Surg A 2007;89(7):1565-74. https://doi.org/10.2106/JBJS.F.00370.

[13] Bylski-Austrow DI, Grood ES, Hefzy MS, Holden JP, Butler DL. Anterior cruciate ligament replacements: a mechanical study of femoral attachment location, flexion angle at tensioning, and initial tension. J Orthop Res 1990;8(4):522-31. https:// doi.org/10.1002/jor.1100080408.

[14] Gertel TH, Lew WD, Lewis JL, Stewart NJ, Hunter RE. Effect of anterior cruciate ligament graft tensioning direction, magnitude, and flexion angle on knee biomechanics. Am J Sports Med 1993;21(4):572-81. https://doi.org/10.1177/ 036354659302100415.

[15] Höher J, Kanamori A, Zeminski J, Fu FH, Woo SLY. The position of the tibia during graft fixation affects knee kinematics and graft forces for anterior cruciate ligament reconstruction. Am J Sports Med 2001;29(6):771-6. https://doi.org/10.1177/ 03635465010290061601.

[16] Debandi A, Maeyama A, Hoshino Y, et al. The influence of knee flexion angle for graft fixation on rotational knee stability during anterior cruciate ligament reconstruction: a biomechanical study. Arthroscopy 2016;32(11):2322-8. https:// doi.org/10.1016/j.arthro.2016.03.018.

[17] Anderson CJ, Westerhaus BD, Pietrini SD, et al. Kinematic impact of anteromedial and posterolateral bundle graft fixation angles on double-bundle anterior cruciate ligament reconstructions. Am J Sports Med 2010;38(8):1575-83. https://doi.org/ 10.1177/0363546510364841.

[18] Koga H, Muneta T, Yagishita K, Ju YJ, Sekiya I. The effect of graft fixation angles on anteroposterior and rotational knee laxity in double-bundle anterior cruciate ligament reconstruction: evaluation using computerized navigation. Am J Sports Med 2012;40(3):615-23. https://doi.org/10.1177/0363546511426696. 
[19] Mae T, Shino K, Nakata K, Toritsuka Y, Otsubo H, Fujie H. Optimization of graft fixation at the time of anterior cruciate ligament reconstruction: Part II: Effect of knee flexion angle. Am J Sports Med 2008;36(6):1094-100. https://doi.org/ 10.1177/0363546508317412.

[20] Miura K, Woo SLY, Brinkley R, Fu YC, Noorani S. Effects of knee flexion angles for graft fixation on force distribution in double-bundle anterior cruciate ligament grafts. Am J Sports Med 2006;34(4):577-85. https://doi.org/10.1177/ 0363546505281814.

[21] Moher D, Liberati A, Tetzlaff J, Altman DG, PRISMA Group. Preferred reporting items for systematic reviews and meta-analyses: the PRISMA statement. PLoS Medicine 2009;6(7):e1000097. https://doi.org/10.1371/journal.pmed.1000097.

[22] Landis JR, Koch GG. The measurement of observer agreement for categorical data. Biometrics 1977;33(1):159-74. pmid: 843571.

[23] Higgins JPT, Altman DG, Gøtzsche PC, et al. The Cochrane Collaboration's tool for assessing risk of bias in randomised trials. BMJ 2011;343:d5928. https://doi.org/ 10.1136/bmj.d5928.

[24] Slim K, Nini E, Forestier D, Kwiatkowski F, Panis Y, Chipponi J. Methodological index for non-randomized studies (MINORS): development and validation of a new instrument. ANZ J Surg 2003;73(9):712-6. https://doi.org/10.1046/j.14452197.2003.02748.x.

[25] Wright J. Levels of evidence and grades of recommendations: an evaluation of literature. Am Acad Orthop Surg 2005:16-8.

[26] Mohtadi N, Chan D, Barber R, Paolucci EO. Reruptures, reinjuries, and revisions at a minimum 2-year follow-up: A randomized clinical trial comparing 3 graft types for ACL reconstruction. Clin J Sport Med 2016;26(2):96-107. https://doi.org/ 10.1097/JSM.0000000000000209.

[27] Koutras G, Papadopoulos P, Terzidis IP, Gigis I, Pappas E. Short-term functional and clinical outcomes after ACL reconstruction with hamstrings autograft: Transtibial versus anteromedial portal technique. Knee Surg Sports Traumatol Arthrosc 2013; 21(8):1904-9. https://doi.org/10.1007/s00167-012-2323-9.

[28] Bedi A, Musahl V, Steuber V, et al. Transtibial versus anteromedial portal reaming in anterior cruciate ligament reconstruction: An anatomic and biomechanical evaluation of surgical technique. Arthroscopy 2011;27(3):380-90. https://doi.org/ 10.1016/j.arthro.2010.07.018.

[29] Akoto R, Hoeher J. Anterior cruciate ligament (ACL) reconstruction with quadriceps tendon autograft and press-fit fixation using an anteromedial portal technique. BMC Musculoskelet Disord 2012;13:161. https://doi.org/10.1186/1471-2474-13-161.

[30] Barié A, Sprinckstub T, Huber J, Jaber A. Quadriceps tendon vs. patellar tendon autograft for ACL reconstruction using a hardware-free press-fit fixation technique: Comparable stability, function and return-to-sport level but less donor site morbidity in athletes after 10 years. Arch Orthop Trauma Surg 2020;140(10): 1465-74. https://doi.org/10.1007/s00402-020-03508-1.

[31] Lee S, Seong SC, Jo H, Park YK, Lee MC. Outcome of anterior cruciate ligament reconstruction using quadriceps tendon autograft. Arthroscopy 2004;20(8): 795-802. https://doi.org/10.1016/j.arthro.2004.06.009.

[32] Lund B, Nielsen T, Faun $\varnothing$ P, Christiansen SE, Lind M. Is quadriceps tendon a better graft choice than patellar tendon? A prospective randomized study. Arthroscopy 2014;30(5):593-8. https://doi.org/10.1016/j.arthro.2014.01.012.

[33] Martin-Alguacil JL, Arroyo-Morales M, Martín-Gomez JL, et al. Strength recovery after anterior cruciate ligament reconstruction with quadriceps tendon versus hamstring tendon autografts in soccer players: A randomized controlled trial. Knee 2018;25(4):704-14. https://doi.org/10.1016/j.knee.2018.03.011.

[34] Perez JR, Emerson CP, Barrera CM, et al. Patient-reported knee outcome scores with soft tissue quadriceps tendon autograft are similar to bone-patellar tendon-bone autograft at minimum 2-year follow-up: A retrospective single-center cohort study in primary anterior cruciate ligament reconstruction. Orthop J Sport Med 2019; 7(12). https://doi.org/10.1177/2325967119890063.

[35] Gorschewsky O, Klakow A, Pütz A, Mahn H, Neumann W. Clinical comparison of the autologous quadriceps tendon (BQT) and the autologous patella tendon (BPTB) for the reconstruction of the anterior cruciate ligament. Knee Surg Sports Traumatol Arthrosc 2007;15(10):1284-92. https://doi.org/10.1007/s00167-007-0371-3.

[36] Kim SJ, Jo SB, Kumar P, Oh KS. Comparison of single- and double-bundle anterior cruciate ligament reconstruction using quadriceps tendon-bone autografts. Arthroscopy 2009;25(1):70-7. https://doi.org/10.1016/j.arthro.2008.09.004.

[37] Cavaignac E, Coulin B, Tscholl P, Nik Mohd Fatmy N, Duthon V, Menetrey J. Is quadriceps tendon autograft a better choice than hamstring autograft for anterior cruciate ligament reconstruction? A comparative study with a mean follow-up of 3.6 years. Am J Sports Med 2017;45(6):1326-32. https://doi.org/10.1177/ 0363546516688665.

[38] Chen CH, Chuang TY, Wang KC, Chen WJ, Shih CH. Arthroscopic anterior cruciate ligament reconstruction with quadriceps tendon autograft: Clinical outcome in 4-7 years. Knee Surg Sports Traumatol Arthrosc 2006;14(11):1077-85. https://doi.org/ 10.1007/s00167-006-0111-0.

[39] Galan H, Escalante M, Della Vedova F, Slullitel D. All inside full thickness quadriceps tendon ACL reconstruction: Long term follow up results. J Exp Orthop 2020;7:13. https://doi.org/10.1186/s40634-020-00226-w.

[40] Geib TM, Shelton WR, Phelps RA, Clark L. Anterior cruciate ligament reconstruction using quadriceps tendon autograft: Intermediate-term outcome. Arthroscopy 2009 25(12):1408-14. https://doi.org/10.1016/j.arthro.2009.06.004.

[41] Han HS, Seong SC, Lee S, Lee MC. Anterior cruciate ligament reconstruction: Quadriceps versus patellar autograft. Clin Orthop Relat Res 2008;466(1):198-204. https://doi.org/10.1007/s11999-007-0015-4.
[42] Kim BH, Kim J Il, Lee O, Lee KW, Lee MC, Han HS. Preservation of remnant with poor synovial coverage has no beneficial effect over remnant sacrifice in anterior cruciate ligament reconstruction. Knee Surg Sports Traumatol Arthrosc 2018;26(8): 2345-52. https://doi.org/10.1007/s00167-017-4683-7.

[43] Kwak YH, Lee S, Lee MC, Han HS. Anterior cruciate ligament reconstruction with quadriceps tendon-patellar bone allograft: Matched case control study. BMC Muscoskel Disord 2018;19(1):45. https://doi.org/10.1186/s12891-018-1959-0.

[44] Lee JK, Lee S, Lee MC. Outcomes of anatomic anterior cruciate ligament reconstruction: Bone-quadriceps tendon graft versus double-bundle hamstring tendon graft. Am J Sports Med 2016;44(9):2323-9. https://doi.org/10.1177/ 0363546516650666.

[45] Nishimoto K, Kuroda R, Mizuno K, et al. Analysis of the graft bending angle at the femoral tunnel aperture in anatomic double bundle anterior cruciate ligament reconstruction: A comparison of the transtibial and the far anteromedial portal technique. Knee Surg Sports Traumatol Arthrosc 2009;17(3):270-6. https:// doi.org/10.1007/s00167-008-0680-1.

[46] Scopp JM, Jasper LE, Belkoff SM, Moorman 3rd CT. The effect of oblique femoral tunnel placement on rotational constraint of the knee reconstructed using patellar tendon autografts. Arthroscopy 2004;20(3):294-9. https://doi.org/10.1016/ j.arthro.2004.01.001.

[47] Marchant BG, Noyes FR, Barber-Westin SD, Fleckenstein C. Prevalence of nonanatomical graft placement in a series of failed anterior cruciate ligament reconstructions. Am J Sports Med 2010;38(10):1987-96. https://doi.org/10.1177/ 0363546510372797.

[48] Rothrauff BB, Jorge A, de Sa D, Kay J, Fu FH, Musahl V. Anatomic ACL reconstruction reduces risk of post-traumatic osteoarthritis: a systematic review with minimum 10-year follow-up. Knee Surg Sports Traumatol Arthrosc 2019;28(4):1072-84. https://doi.org/ 10.1007/s00167-019-05665-2.

[49] Scanlan SF, Donahue JP, Andriacchi TP. The in vivo relationship between anterior neutral tibial position and loss of knee extension after transtibial ACL reconstruction. Knee 2014;21(1):74-9. https://doi.org/10.1016/ j.knee.2013.06.003.

[50] Riboh JC, Hasselblad V, Godin JA, Mather 3rd RC. Transtibial versus independent drilling techniques for anterior cruciate ligament reconstruction: A systematic review, meta-analysis, and meta-regression. Am J Sports Med 2013;41(11): 2693-702. https://doi.org/10.1177/0363546513506979.

[51] Chen H, Tie K, Qi Y, Li B, Chen B, Chen L. Anteromedial versus transtibial technique in single-bundle autologous hamstring ACL reconstruction: A meta-analysis of prospective randomized controlled trials. J Orthop Surg Res 2017;12:167. https:// doi.org/10.1186/s13018-017-0671-3.

[52] Shen C, Jiang SD, Jiang LS, Dai LY. Bioabsorbable versus metallic interference screw fixation in anterior cruciate ligament reconstruction: A meta-analysis of randomized controlled trials. Arthroscopy 2010;26(5):705-13. https://doi.org/ 10.1016/j.arthro.2009.12.011.

[53] Emond CE, Woelber EB, Kurd SK, Ciccotti MG, Cohen SB. A comparison of the results of anterior cruciate ligament reconstruction using bioabsorbable versus metal interference screws: A meta-analysis. J Bone Jt Surg A 2011;93(6):572-80. https://doi.org/10.2106/JBJS.J.00269.

[54] Mascarenhas R, Saltzman BM, Sayegh ET, et al. Bioabsorbable versus metallic interference screws in anterior cruciate ligament reconstruction: A systematic review of overlapping meta-analyses. Arthroscopy 2015;31(3):561-8. https:// doi.org/10.1016/j.arthro.2014.11.011.

[55] Crum RJ, De Sa D, Kanakamedala AC, Obioha OA, Lesniak BP, Musahl V. Aperture and suspensory fixation equally efficacious for quadriceps tendon graft fixation in primary ACL reconstruction: A systematic review. J Knee Surg 2020;33(7):704-21. https://doi.org/10.1055/s-0039-1685160.

[56] Jagodzinski M, Geiges B, Von Falck C, et al. Biodegradable screw versus a press-fit bone plug fixation for hamstring anterior cruciate ligament reconstruction: A prospective randomized study. Am J Sports Med 2010;38(3):501-8. https:// doi.org/10.1177/0363546509350325.

[57] de Sa D, Arakgi ME, Kanakamedala AC, Obioha O, Lesniak BP, Musahl V. No difference between full- and partial-thickness quadriceps autograft in ACL reconstruction. Sport Orthop Traumatol 2018;34(2):186. https://doi.org/10.1016/ j.orthtr.2018.03.049.

[58] Irrgang JJ, Anderson AF, Boland AL, et al. Development and validation of the international knee documentation committee subjective knee form. Am J Sports Med 2001;29(5):600-13. https://doi.org/10.1177/03635465010290051301.

[59] Collins NJ, Misra D, Felson DT, Crossley KM, Roos EM. Measures of knee function: international knee documentation committee (IKDC) subjective knee evaluation form, knee injury and osteoarthritis outcome score (KOOS), knee injury and osteoarthritis outcome score physical function short form (KOOS-PS). Arthritis Care Res 2011;63(Suppl 1):S208-28. https://doi.org/10.1002/acr.20632.

[60] Tegner Y, Lysholm J. Rating systems in the evaluation of knee ligament injuries. Clin Orthop Relat Res 1985;198:42-9. https://doi.org/10.1097/00003086198509000-00007.

[61] Kocher MS, Steadman JR, Briggs KK, Sterett WI, Hawkins RJ. Reliability, validity, and responsiveness of the Lysholm knee scale for various chondral disorders of the knee. J Bone Joint Surg Am 2004;86(6):1139-45. https://doi.org/10.2106/ 00004623-200406000-00004.

[62] Noyes FR, Grood ES, Wilfredo Suntay PJ, Butler DL. The three dimensional laxity of the anterior cruciate deficient knee as determined by clinical laxity tests. Iowa Orthop J 1983;3:32-4. 